九州大学学術情報リポジトリ

Kyushu University Institutional Repository

\title{
High-efficiency red electrophosphorescence devices
}

Adachi, Chihaya

Center for Photonics and Optoelectronic Materials (POEM), Department of Electrical Engineering and the Princeton Materials Institute, Princeton University

Baldo, Marc. A.

Center for Photonics and Optoelectronic Materials (POEM), Department of Electrical Engineering and the Princeton Materials Institute, Princeton University

Forrest, Stephen R.

Center for Photonics and Optoelectronic Materials (POEM), Department of Electrical Engineering and the Princeton Materials Institute, Princeton University

\section{Lamansky, Sergey}

Department of Chemistry, University of Southern California

他

http://hdl. handle. net/2324/19448

出版情報: Applied Physics Letters. 78 (11)，pp.1622-1624，2001-03-12. American Institute of Physics

バージョン :

権利関係: Copyright 2001 American Institute of Physics. This article may be downloaded for personal use only. Any other use requires prior permission of the author and the American Institute of Physics. 


\title{
High-efficiency red electrophosphorescence devices
}

\author{
Chihaya Adachi, Marc A. Baldo, and Stephen R. Forrest ${ }^{\mathrm{a})}$ \\ Center for Photonics and Optoelectronic Materials (POEM), Department of Electrical Engineering, \\ Princeton University, Princeton, New Jersey 08544 \\ Sergey Lamansky and Mark E. Thompson \\ Department of Chemistry, University of Southern California, Los Angeles, California 90089
}

Raymond C. Kwong

Universal Display Corporation, 375 Phillips Boulevard, Ewing, New Jersey 08618

(Received 1 December 2000; accepted for publication 16 January 2001)

\begin{abstract}
We demonstrate high-efficiency red electrophosphorescent organic light-emitting devices employing bis $\left(2-\left(2^{\prime}\right.\right.$-benzo[ 4,5 -a]thienyl)pyridinato- $\left.\mathrm{N}, \mathrm{C}^{3^{\prime}}\right)$ iridium(acetylacetonate) $\left[\mathrm{Btp} \mathrm{t}_{2} \operatorname{Ir}(\mathrm{acac})\right]$ as a red phosphor. A maximum external quantum efficiency of $\eta_{\mathrm{ext}}=(7.0 \pm 0.5) \%$ and power efficiency of $\eta_{p}=(4.6 \pm 0.5) \mathrm{lm} / \mathrm{W}$ are achieved at a current density of $J=0.01 \mathrm{~mA} / \mathrm{cm}^{2}$. At a higher current density of $J=100 \mathrm{~mA} / \mathrm{cm}^{2}, \quad \eta_{\mathrm{ext}}=(2.5 \pm 0.3) \%$ and $\eta_{p}=(0.56 \pm 0.05) \mathrm{lm} / \mathrm{W}$ are obtained. The electroluminescent spectrum has a maximum at a wavelength of $\lambda_{\max }=616 \mathrm{~nm}$ with additional intensity peaks at $\lambda_{\text {sub }}=670$ and $745 \mathrm{~nm}$. The Commission Internationale de L'Eclairage coordinates of $(x=0.68, y=0.32)$ are close to meeting video display standards. The short phosphorescence lifetime $(\sim 4 \mu \mathrm{s})$ of $\operatorname{Btp}_{2} \operatorname{Ir}(\mathrm{acac})$ leads to a significant improvement in $\eta_{\mathrm{ext}}$ at high currents as compared to the previously reported red phosphor, 2,3,7,8,12,13,17,18-octaethyl-12H, $23 \mathrm{H}$-prophine platinum (II) PtOEP with a lifetime of $\sim 50 \mu \mathrm{s}$. (C) 2001 American Institute of Physics. [DOI: 10.1063/1.1355007]
\end{abstract}

Heavy-metal complexes, ${ }^{1,2}$ where strong spin-orbit coupling leads to singlet-triplet state mixing, can result in highefficiency electrophosphorescence in organic light-emitting devices (OLEDs). ${ }^{3-6}$ For example, OLEDs employing the phosphor, factris(2-phenylpyridine)iridium $\left[\operatorname{Ir}(\mathrm{ppy})_{3}\right]$, exhibit green emission with an external quantum efficiency $\left(\eta_{\text {ext }}\right)$ of $\sim 15 \% .^{6}$ By designing appropriate ligands for heavy-metal complexes, high-efficiency electrophosphorescence at other emission colors is anticipated for highperformance full-color display applications. ${ }^{7}$ Both redemitting fluorescent and phosphorescent dopants have shown promise for use in OLEDs. While fluorescent dyes, including 4-dicyanomethylene-2-methyl-6-[2-(2,3,6,7-tetra-hydro-1H, 5H-benzo[ij]quinolizin-8-yl)-4H-pyran (DCM2) $)^{8,9}$ and porphyrin derivatives (TPP, ${ }^{10} \mathrm{ZnTPP},{ }^{11}$ and $\mathrm{TPC}^{12}$ ), have been investigated, their maximum external quantum efficiencies are limited to less than $1 \%$. Furthermore, the red phosphorescent europium complexes $\left(\mathrm{EuL}_{3}\right)^{13,14}$ and 2,3,7,8,12,13,17,18-octaethyl-12H,23H-porphine platinum (II) (PtOEP) have been studied. ${ }^{3,4}$ Although $\mathrm{EuL}_{3}$ complexes show very strong red $\mathrm{Eu}^{3+}$ ion emission (with an internal quantum efficiency $\left.\eta_{\text {int }}>80 \%\right),{ }^{15}$ the long lifetime of the $\mathrm{Eu}^{3+}$ excited state $(\sim 350 \mu \mathrm{s})$ results in pronounced triplettriplet $(\mathrm{T}-\mathrm{T})$ annihilation at high current. ${ }^{14}$ In addition, the high triplet energy of the ligands causes backward energy transfer to the host molecule, leading to $\eta_{\mathrm{ext}}<1.4 \% .{ }^{14}$ The highest $\eta_{\mathrm{ext}}=5.6 \%$ for a red phosphor has been achieved with PtOEP doped into 4,4'-N,N'-dicarbazole-biphenyl.

${ }^{a)}$ Electronic mail: forrest@ee.princeton.edu
(CBP). ${ }^{4}$ However, the relatively long phosphorescence lifetime $(\sim 80 \mu \mathrm{s})$ again results in $\mathrm{T}-\mathrm{T}$ annihilation at high current. $^{16}$

In this study, we demonstrate red organometallic phosphors characterized by a high quantum efficiency and a short radiative lifetime. ${ }^{17}$ The metal complexes contain cyclometalated benzothienylpyridine ligands, i.e., bis $\left(2-\left(2^{\prime}\right.\right.$-benzo $[4,5-\alpha]$ thienyl $)$ pyridinato- $\left.\mathrm{N}, \mathrm{C}^{3^{\prime}}\right)$ iridium (acetyl-acetonate) $\quad\left[\mathrm{btp}_{2} \operatorname{Ir}(\mathrm{acac})\right]^{7}$ and $\quad\left(2-\left(2^{\prime}\right.\right.$-benzo $[4$, $5-\alpha]$ thienyl)pyridinato- $\mathrm{N}, \mathrm{C}^{3^{\prime}}$ ) platinum (acetylacetonate) [btpt(acac)], shown in Fig. 1. The synthesis of btpPt(acac) was prepared by a method analogous to that used ${ }^{7}$ for btp $_{2} \operatorname{Ir}(\mathrm{acac})$. The small $\pi-\pi^{*}$ transition energy of the btp ligand relative to other ligands used in heavy-metal phosphors leads to a low-energy triplet excited state, giving strong red phosphorescence. OLEDs employing these phosphors were grown by high vacuum $\left(10^{-6}\right.$ Torr $)$ thermal evaporation onto pre-cleaned glass substrates as described elsewhere. ${ }^{6}$ Device I is comprised of a $20 \Omega / \square$ indium tin oxide (ITO) anode, a 50-nm-thick 4,4'-bis[N-(1-naphthyl)$\mathrm{N}$-phenyl-amino]biphenyl hole transport layer (HTL), a 20nm-thick light-emitting layer (EML) consisting of a conductive CBP host doped with $\sim 7 \%$ of the guest phosphor, a 10-nm-thick 2,9-dimethyl-4,7-diphenyl-phenanthroline hole and exciton blocking layer, ${ }^{4}$ a 65 -nm-thick tris(8hydroxyquinoline)aluminum $\left(\mathrm{Alq}_{3}\right)$ electron transport layer (ETL), and a cathode comprised of a 100-nm-thick (10:1) $\mathrm{MgAg}$ layer, with a further $20 \mathrm{~nm} \mathrm{Ag}$ deposited as a protective cap (Fig. 1). Device II has the ITO anode, a 60-nm-thick 4,4'-bis[N,N $\mathrm{N}^{\prime}$-(3-tolyl)amino]-3,3'-dimethylbiphenyl ${ }^{6}$ HTL, a 25-nm-thick 2,2',2' -(1,3,5-benzenetriyl)tris[1-phenyl$1 H$-benzimidazole] (TPBI) ${ }^{18}$ EML doped with $\sim 7 \%$ phos- 


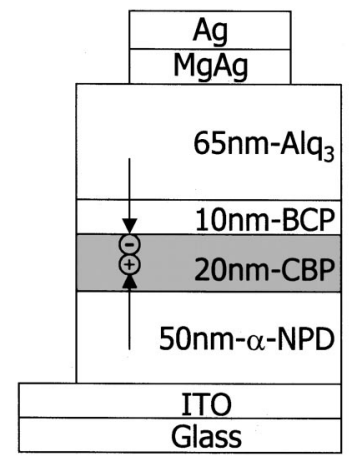

Device I

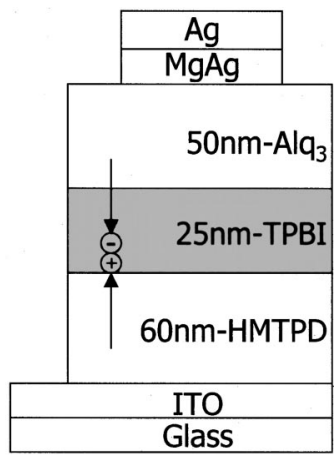

Device II

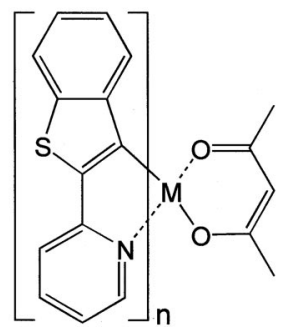

FIG. 1. Device structures $\underline{I}$ and II. Molecular structure of the btp ${ }_{2} \mathrm{M}(\mathrm{acac})$ phosphors (here $M=\mathrm{Ir}, n=2$ and $M=\mathrm{Pt}, n=1$ ).

phor, a 50-nm-thick $\mathrm{Alq}_{3}$ ETL, and the same cathode as in device I.

Figure 2 shows $\eta_{\text {ext }}$ and the power efficiency $\left(\eta_{p}\right)$ as functions of current density for device $\underline{I}$ with a btp ${ }_{2} \operatorname{Ir}($ acac $)$ guest. A maximum $\eta_{\text {ext }}=(7.0 \pm 0.5) \%$ and $\eta_{p}=(4.6$ $\pm 0.5) \mathrm{lm} / \mathrm{W}$, and a luminance of $6.5 \mathrm{~cd} / \mathrm{m}^{2}$ were obtained at $J=0.1 \mathrm{~mA} / \mathrm{cm}^{2}$. The device showed a gradual decrease of $\eta_{\text {ext }}$ with increasing current, which has been previously attributed to T-T annihilation. ${ }^{14,19}$ Nevertheless, at $J$ $=100 \mathrm{~mA} / \mathrm{cm}^{2}$, the device efficiency remained high at $\eta_{\text {ext }}$ $=(2.5 \pm 0.3) \%$ and $\eta_{p}=(0.56 \pm 0.05) \mathrm{lm} / \mathrm{W}$. A maximum luminance of $6800 \mathrm{~cd} / \mathrm{m}^{2}$ was obtained at $J=690 \mathrm{~mA} / \mathrm{m}^{2}$.

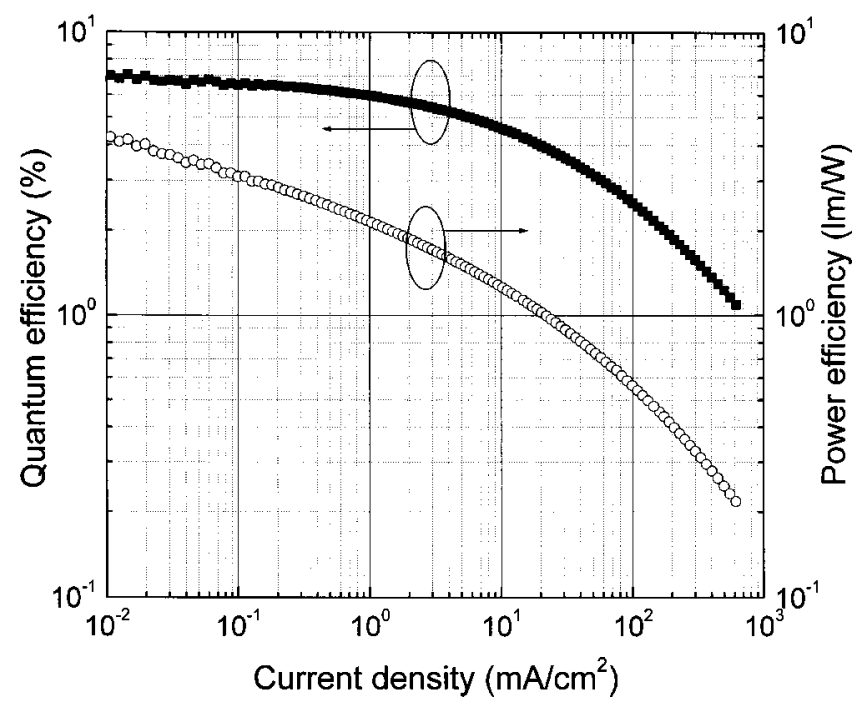

FIG. 2. External quantum efficiency $\left(\eta_{\text {ext }}\right)$ and power efficiency $\left(\eta_{\mathrm{p}}\right)$ vs current density for device $\underline{I}$ with a btp ${ }_{2} \operatorname{Ir}(\mathrm{acac})$ guest.

Table I summarizes the electroluminescence characteristics of btp $_{2} \operatorname{Ir}(\mathrm{acac})$, btpPt(acac), PtOEP and Eu(TTA) $)_{3}$ phen ( TTA $=$ thenoyltrifluoroacetone, phen $=1,10$-phenanthroline) guests in devices I and II. A maximum $\eta_{\text {ext }} \sim 7 \%$ was ob-

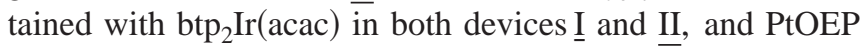
in device II. Also, the maximum $\eta_{p}$ of btp $\mathrm{p}_{2} \operatorname{Ir}(\mathrm{acac})$ was $(4.6 \pm 0.5) \bar{l} \mathrm{~m} / \mathrm{W}$ which is significantly higher than that of PtOEP, since the spectral peak of the latter compound is $\sim 30$ $\mathrm{nm}$ redshifted relative to $\mathrm{btp}_{2} \operatorname{Ir}(\mathrm{acac})$. A pronounced improvement in $\eta_{\text {ext }}$ of btp br $_{2} \operatorname{Irac}$ ) was observed at high current. At $J=100 \mathrm{~mA} / \mathrm{cm}^{2}$, the $b_{t}{ }_{2} \operatorname{Ir}(\mathrm{acac})$ doped device $\underline{I}$ showed a relatively high $\eta_{\text {ext }}=(2.5 \pm 0.5) \%$, compared with PtOEP and Eu(TTA $)_{3}$ phen doped devices $\underline{I}$ with $\eta_{\text {ext }}=(0.61$ $\pm 0.05) \%$ and $\eta_{\text {ext }}=(0.21 \pm 0.05) \%$, respectively. The roll off in $\eta_{\text {ext }}$ with $J$ is consistent with the electrophosphorescent lifetimes, $\tau$, of the several materials employed. As shown

TABLE I. Red electrophosphorescent OLED characteristics. External quantum efficiency ( $\eta_{\text {ext }}$ ), and power efficiency $\left(\eta_{\mathrm{p}}\right)$ are given as functions of current density. Peak wavelength $\left(\lambda_{\max }\right)$ in electroluminescent spectrum. Transient electrophosphorescent time $(\tau)$ under electrical pulse excitation with pulse width of $500 \mathrm{~ns}$. The characteristic current $\left(J_{0}\right)$ of triplet-triplet annihilation.

\begin{tabular}{|c|c|c|c|c|c|c|c|c|c|c|}
\hline & & \multicolumn{6}{|c|}{$\begin{array}{c}\eta_{\mathrm{ext}}(\%) \\
{\left[\eta_{\mathrm{p}}(\mathrm{lm} / \mathrm{W})\right] \text { at } J\left(\mathrm{~mA} / \mathrm{cm}^{2}\right)}\end{array}$} & \multirow[b]{2}{*}{$\lambda_{\max }(\mathrm{nm})$} & \multirow[b]{2}{*}{$\tau(\mu \mathrm{s})$} & \multirow[b]{2}{*}{$J_{0}\left(\mathrm{~mA} / \mathrm{cm}^{2}\right)$} \\
\hline & & $J=0.01$ & 0.1 & 1 & 10 & 100 & 1000 & & & \\
\hline \multirow{3}{*}{$\mathrm{Btp}_{2} \operatorname{Ir}(\mathrm{acac})$} & Device I & $\begin{array}{c}7.0 \\
(4.6)\end{array}$ & $\begin{array}{c}6.7 \\
(3.1)\end{array}$ & $\begin{array}{c}6.0 \\
(2.1)\end{array}$ & $\begin{array}{c}4.4 \\
(1.3)\end{array}$ & $\begin{array}{l}2.5 \\
(0.56)\end{array}$ & $\begin{array}{c}0.69 \\
(0.16)\end{array}$ & \multirow{3}{*}{616} & 6.5 & 27.4 \\
\hline & & & & & & & & & & \\
\hline & Device II & $\begin{array}{c}6.9 \\
(5.7)\end{array}$ & $\begin{array}{c}6.8 \\
(3.6)\end{array}$ & $\begin{array}{c}5.9 \\
(2.5)\end{array}$ & $\begin{array}{c}3.7 \\
(1.4)\end{array}$ & $\begin{array}{l}1.6 \\
(0.57)\end{array}$ & $\begin{array}{c}0.53 \\
(0.14)\end{array}$ & & 4.0 & 11.0 \\
\hline \multirow{3}{*}{ BtpPt(acac) } & Device I & $\begin{array}{c}2.7 \\
(2.5)\end{array}$ & $\begin{array}{c}2.7 \\
(1.4)\end{array}$ & $\begin{array}{l}2.6 \\
(0.93)\end{array}$ & $\begin{array}{l}1.9 \\
(0.54)\end{array}$ & $\begin{array}{l}1.0 \\
(0.25)\end{array}$ & $\begin{array}{l}0.37 \\
(0.083)\end{array}$ & \multirow{3}{*}{610} & 9.3 & 37.7 \\
\hline & & & & & & & & & & \\
\hline & Device II & $\begin{array}{c}2.2 \\
(1.7)\end{array}$ & $\begin{array}{c}2.2 \\
(1.1)\end{array}$ & $\begin{array}{l}2.1 \\
(0.72)\end{array}$ & $\begin{array}{l}1.3 \\
(0.34)\end{array}$ & $\begin{array}{c}0.57 \\
(0.12)\end{array}$ & $\begin{array}{c}0.0 .2 \\
(0.036)\end{array}$ & & 5.6 & 14.5 \\
\hline \multirow{3}{*}{ PtOEP } & Device I & $\begin{array}{c}5.2 \\
(1.3)\end{array}$ & $\begin{array}{c}5.2 \\
(1.1)\end{array}$ & $\begin{array}{l}4.1 \\
(0.64)\end{array}$ & $\begin{array}{l}2.1 \\
(0.25)\end{array}$ & $\begin{array}{l}0.67 \\
(0.066)\end{array}$ & $\begin{array}{c}0.18 \\
(0.015)\end{array}$ & \multirow{3}{*}{650} & 86.5 & 6.4 \\
\hline & & & & & & & & & & \\
\hline & Device II & $\begin{array}{c}6.9 \\
(1.4)\end{array}$ & $\begin{array}{c}6.9 \\
(1.0)\end{array}$ & $\begin{array}{c}4.3 \\
(0.53)\end{array}$ & $\begin{array}{l}1.9 \\
(0.17)\end{array}$ & $\begin{array}{l}0.5 \\
(0.039)\end{array}$ & $\begin{array}{c}0.10 \\
(0.010)\end{array}$ & & 49.6 & 2.6 \\
\hline $\begin{array}{l}\mathrm{Eu}(\mathrm{TTA})_{3} \\
\text { phen }\end{array}$ & Device I & $\begin{array}{c}1.4 \\
(1.2)\end{array}$ & $\begin{array}{l}1.3 \\
(0.94)\end{array}$ & $\begin{array}{c}1.2 \\
(0.53)\end{array}$ & $\begin{array}{c}0.68 \\
(0.21)\end{array}$ & $\begin{array}{c}0.21 \\
(0.08)\end{array}$ & $\cdots$ & 614 & 350 & 3.6 \\
\hline
\end{tabular}




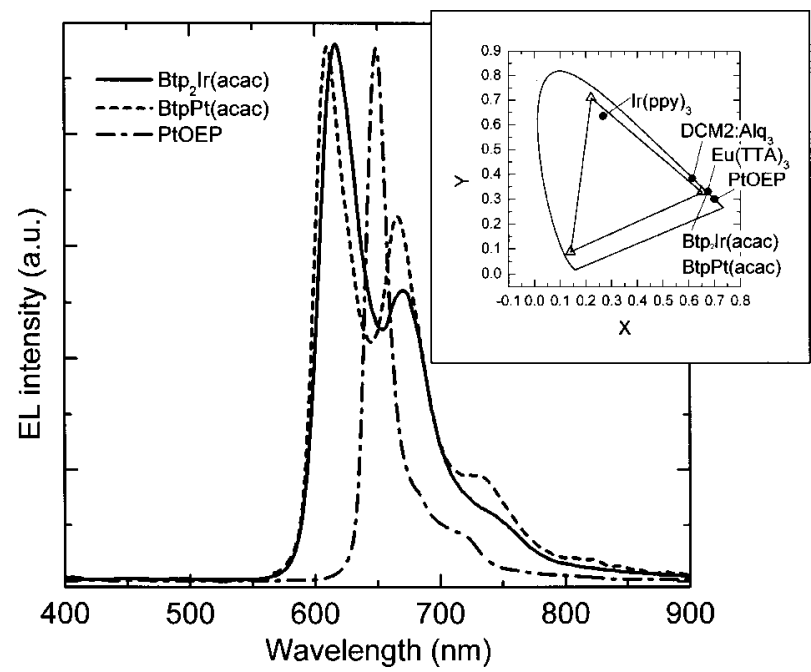

FIG. 3. Electroluminescent spectra of device II employing btp $2 \operatorname{Ir}(a c a c)$, PtOEP or btpPt(acac) at a current density of $\bar{J}=1.3 \mathrm{~mA} / \mathrm{cm}^{2}$. Inset: CIE coordinates for $\operatorname{btp}_{2} \operatorname{Ir}(\mathrm{acac})(x=0.67, y=0.33), \operatorname{btpPt}(\mathrm{acac})(x=0.67, y$ $=0.33)$, PtOEP $(x=0.70, y=0.30)$ and $\mathrm{Eu}(\mathrm{TTA})_{3}$ phen $(x=0.68, y$ $=0.32)$ doped devices and a $2 \%$-DCM2: $\operatorname{Alq}_{3}(x=0.61, y=0.39)$ device. The triangles show the NTSC recommended blue, green, and red coordinates.

previously, the characteristic current $\left(J_{0}\right)$ at which $\eta_{\text {ext }}$ falls to $50 \%$ its peak value due to $\mathrm{T}-\mathrm{T}$ annihilation is inversely proportional to $\tau^{2} .{ }^{14,19}$ This figure of merit of a phosphor is listed in Table I along with $\tau$ for the devices tested. The $\mathrm{btp}_{2} \operatorname{Ir}(\mathrm{acac})$ lifetime is $\sim 12$ times smaller than that of PtOEP, leading to considerably improved high-current performance of the Ir-based compound. The low $\eta_{\text {ext }}$ of btpPt(acac) is consistent with its low photoluminescence efficiency $[(8 \pm 2) \%]$ compared with that of $b_{2 t} \operatorname{Ir}(\mathrm{acac})$ $[(21 \pm 5) \%]$ and PtOEP $[(40 \pm 10) \%]$.

The EL spectra originating from the triplet-excited states of the phosphors shown in Fig. 3 are coincident with those of the phosphors in a dilute solution. The Commission Internationale de L'Eclairage (CIE) coordinates for the four devices are compared with a fluorescent $2 \%$-DCM2: $\mathrm{Alq}_{3}$ device $(x$ $=0.61,0.39)$ (inset of Fig. 2). Similar to the Eu(TTA) ${ }_{3}$ phen of $(x=0.68, y=0.32)$, the $\mathrm{btp}_{2} \operatorname{Ir}(\mathrm{acac})$ and $\operatorname{btpPt}(\mathrm{acac})$ doped devices demonstrate a saturated red emission $(x=0.67, y$ $=0.33$ ) which is close to the National Television Standards Committee recommended red for a video display. Furthermore, the EL spectra and CIE coordinates of btp $\mathrm{p}_{2} \operatorname{Ir}(\mathrm{acac})$ in devices I and II are independent of current (Fig. 4). Even at $J>100 \mathrm{~mA} / \mathrm{cm}^{2}$, blue emission from either the CBP or TPBI host is negligible, indicating complete energy transfer under the excitation conditions used: a direct consequence of the short phosphor lifetime of this compound. ${ }^{20}$

In summary, we demonstrated high-efficiency, highbrightness red phosphorescent OLEDs employing benzothienylpyridine (btp) as a ligand in iridium and platinum complexes. Significant improvements in $\eta_{\text {ext }}$ as compared with PtOEP were achieved due to the short phosphorescence lifetimes of $<10 \mu$ s of the new compounds studied, thereby minimizing $\mathrm{T}-\mathrm{T}$ annihilation and saturation of the ligand excited state.

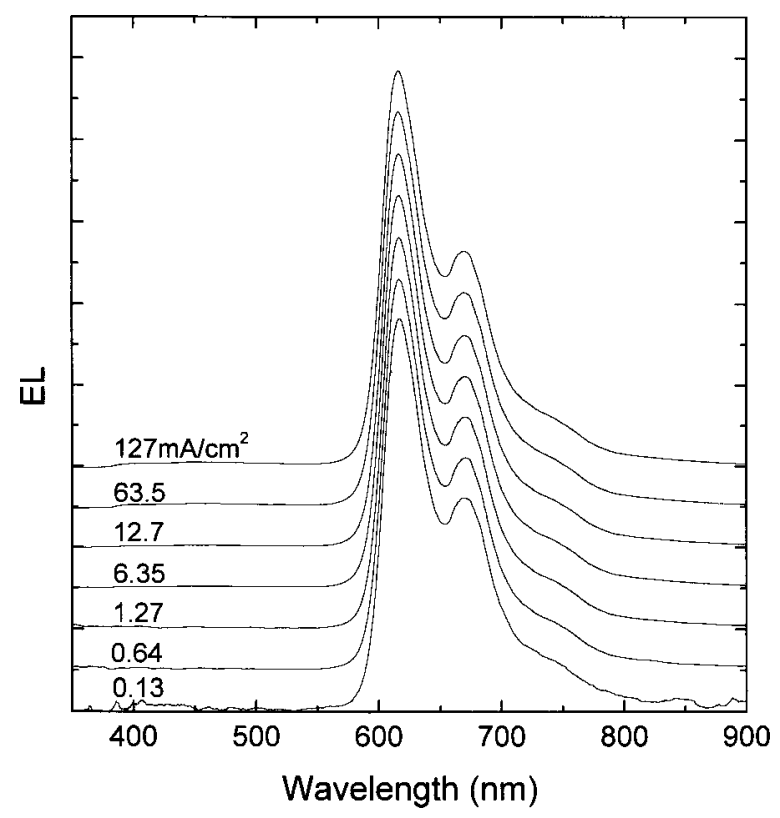

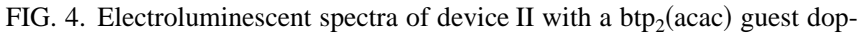
ant as a function of OLED drive current density.

This work was funded by Universal Display Corporation, the Defense Advanced Research Projects Agency, and the Air Force Office of Scientific Research.

${ }^{1}$ J.-M. Lehn, Supermolecular Chemistry (VCH, Weinheim, Germany, 1995).

${ }^{2}$ C. A. Bignozzi, J. R. Schoonover, and F. Scandola, Prog. Inorg. Chem. 44, 1 (1997).

${ }^{3}$ M. A. Baldo, D. F. O’Brien, Y. You, A. Shoustikov, S. Sibley, M. E. Thompson, and S. R. Forrest, Nature (London) 395, 151 (1998).

${ }^{4}$ D. F. O'Brien, M. A. Baldo, M. E. Thompson, and S. R. Forrest, Appl. Phys. Lett. 74, 442 (1999).

${ }^{5}$ M. A. Baldo, S. Lamansky, P. E. Burrows, M. E. Thompson, and S. R. Forrest, Appl. Phys. Lett. 75, 4 (1999).

${ }^{6}$ C. Adachi, M. A. Baldo, and S. R. Forrest, Appl. Phys. Lett. 77, 904 (2000).

${ }^{7}$ S. Lamansky, P. Djurovich, D. Murphy, F. Abdel-Razzaq, H.-E. Lee, C. Adachi, P. E. Burrows, S. R. Forrest, and M. E. Thompson, J. Am. Chem. Soc. (submitted)

${ }^{8}$ C. W. Tang, SID Digest 96, 181 (1996).

${ }^{9}$ Y. Hamada, H. Kanno, T. Tsujioka, H. Takahashi, and T. Usuki, Appl. Phys. Lett. 75, 1682 (1999).

${ }^{10}$ P. E. Burrows, S. R. Forrest, S. P. Sibley, and M. E. Thompson, Appl. Phys. Lett. 69, 2959 (1996).

${ }^{11}$ Y. Hamada, IEEE Trans. Electron Devices 44, 1208 (1997).

${ }^{12}$ Y. Sakakibara, S. Okutsu, T. Enokida, and T. Tani, Appl. Phys. Lett. 74, 2587 (1999).

${ }^{13}$ J. Kido, H. Hayase, K. Hongawa, K. Nagai, and K. Okamoto, Appl. Phys. Lett. 65, 2124 (1994).

${ }^{14}$ C. Adachi, M. A. Baldo, and S. R. Forrest, J. Appl. Phys. 87, 8049 (2000).

${ }^{15}$ G. L. J. A. Rikken, Phys. Rev. A 51, 4906 (1995).

${ }^{16}$ M. A. Baldo, M. E. Thompson, and S. R. Forrest, Nature (London) 403, 750 (2000).

${ }^{17}$ B. W. D'Andrade, M. A. Baldo, C. Adachi, M. E. Thompson, and S. R. Forrest (unpublished).

${ }^{18}$ Y. T. Tao, E. Balasubramaniam, A. Danel, B. Jarosz, and P. Tomasik, Appl. Phys. Lett. 77, 1575 (2000).

${ }^{19}$ M. A. Baldo, C. Adachi, and S. R. Forrest, Phys. Rev. B 62, 10967 (2000).

${ }^{20}$ R. C. Kwong, S. Sibley, T. Dubovoy, M. A. Baldo, S. R. Forrest, and M. E. Thompson, Chem. Mater. 11, 3709 (1999). 